\title{
The Influence Of Cultural Thinking Style On Consumer Cognitive Complexity Underlying Wine Purchase Decisions
}

\author{
Byung-Joon Choi, Pantheon-Assas Paris II University, France
}

\begin{abstract}
Drawing on the cultural priming paradigm, the purpose of this research is to investigate how cultural differences in cognition affect consumers' hierarchical cognitive structures underlying wine purchase decision-making process. Means-end chain analyses of French and Korean wine consumers were conducted both at a chronic cultural difference level and at an experimental level in which either analytic or holistic thinking tendency is primed. The results show that the holistic thinking-primed consumers consider broader connections between the key perceptual elements of the means-end chain, resulting in more complex structures of interconnected motives than the analytic thinking-primed consumers. This study provides support for the dynamics of culture-specific thinking styles as the driver of cultural variations in wine consumers' cognitive complexity in the decision-making process. Important practical implications for international food marketing managers stem from our cross-cultural findings.
\end{abstract}

Keywords: Cultural Thinking Style; Wine-Buying Decision-Making; Cognitive Linkages; Consumer Cognition

\section{INTRODUCTION}

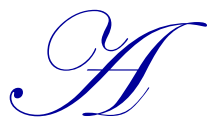
s recalled in Gutman's (1982) article on consumer categorization processes, knowing that consumers want to look well-dressed does not tell us much unless we know why they want to look that way. This is why marketing researchers stress the importance of reflecting on a product in terms of its benefits (desired consequences), not only its attributes (Peter \& Olson, 2005). Instead of perceiving the product as a set of tangible attributes (e.g., price, color), it is deemed appropriate to develop and promote it in the light of the consequences that it has for the consumer (Reynolds, 1985). From this perspective, focusing on the consumer, the consequences of consuming the product determine the relative importance of specific attributes of the product. Other than practical and functional consequences (e.g., comfort, ease-of-use), consumers also expect to experience certain psychological consequences, namely the satisfaction of certain values (e.g., happiness, security) that are often recognized as their motivational orientation in the purchase decision process (Peter \& Olson, 2005). Associating consumers' pursuit of the realization of values with product attributes and the consequences of consumption should thus provide a better understanding of both product and consumer characteristics, in particular the motivations driving consumers' buying behavior.

Means-end chain (MEC) theory is grounded in a cognitive approach emphasizing connections between the attributes of the product, the consequences of consumption, and the corresponding instrumentality of satisfying consumer values (Gutman, 1982). Taking this hierarchical cognitive structure into account in cross-cultural contexts can lead to deeper understanding of international consumer behavior concerning product choice and consumption decisions. Food marketing is an area in which the MEC approach has received considerable attention from consumer marketing academics and practitioners. To date, however, international and cross-cultural applications of MEC theory have been conducted primarily by Western researchers with Anglo-Saxon consumers as subjects (e.g., Grunert et al., 2001; Hofstede, Steenkamp, \& Wedel, 1999; Mort \& Rose, 2004; Overby, Gardial, \& Woodruff, 2004; Russel et al., 2004; Valette-Florence et al., 2000). In addition, little attention has been paid to consumers' cognitive processing styles, which determine different patterns of thinking, in comparative analyses of MECs among consumers from different cultural backgrounds, particularly Western and Eastern cultures. This is despite the fact that a growing corpus of cross-cultural psychology studies confirms cultural differences in styles of thinking, with 
Western societies characterized by analytic thinking and Eastern societies characterized by holistic thinking (Nisbett et al., 2001). Analytic thinking is a cognitive style that separates the object from a given environment and context, and ignores situational variance to focus on a salient object and its attributes. In contrast, holistic thinking is a cognitive style that understands the object in a more global manner by attending to the entire field, and to relationships between an object and its surrounding context.

We suggest that this cultural orientation in the different styles of thinking influences the hierarchical cognitive structure on which consumers from Eastern versus Western cultures base their purchase decision-making process. Thus, the question we address in this research is whether analytic versus holistic thinking affects the manner in which consumers cognitively link product attributes to different consequences and values. More precisely, this research aims to contribute to recent food-related MEC research by examining the relation between cultural differences in cognition between Western (French) and Eastern (Korean) cultural members and their MEC linkages underlying wine purchase decision. The consumption of wine in Korea is relatively new and young but the market is showing continuous growth in recent years. This country today is the third largest wine market in Asia after China and Japan. According to the IWSR (2015), renewed growth in Korean wine consumption will get faster by $14.4 \%$ between 2013 and 2017 to reach a total of 3.98 million nine-liter cases, the equivalent of 47.78 million bottles of wine. The latest statistics from Korea International Trade Association show that France remained the leading supplier of wine to Korea in 2014 with a 30.5 percent market share in terms of value. Using wine as the focal product, this study is to our knowledge the first of its kind to explore the influence of cultural thinking style on MEC linkages of two culturally distinct consumer groups. Our research was undertaken at two different levels of crosscultural analysis: a chronic cultural difference level and an experimental level in which either the analytic or the holistic thinking tendency is primed.

\section{LITERATURE REVIEW AND HYPOTHESIS DEVELOPMENT}

\section{Understanding Consumer Decision-Making with Means-End Approach}

The objective of MEC theory is to explain the behavioral motivation to consume by interpreting the hierarchical MEC relationship linking the attributes of a product and the consumer consequences attributable to these product characteristics; the consequences are in turn related to certain values that render them relevant for the consumer (Olson \& Reynolds, 1983). According to the theory, consumers strive to meet their immediate physiological needs associated with product-specific characteristics, but more importantly, they pursue a set of specific benefits accruing from the product's use and values considered to be a primary driver of product choice. Hence, the central aspect of MEC is that consumers buy products not for the sake of their attributes but for several other reasons, such as the consequences of these attributes and the subsequent instrumentality in satisfying important values (Gutman, 1982). MEC theory argues that consumption decisions are derived from how consumers cognitively evaluate their motivation to consume and relate the product to themselves. The term "means-end" therefore originates from the assumption that a product's attributes or the expected consequences of its consumption are the "means" for the consumer to satisfy his or her "ends", namely the realization of desired goals or values. The three hierarchical levels (attributes, consequences, values) are ordered according to their degree of abstraction and are connected to each other in the sense that the lower levels of the MEC are the means by which the higher levels of the MEC are attained.

In the literature, several approaches have been suggested for uncovering these levels of abstraction among consumers. Laddering is the technique most commonly applied as a means of revealing consumers' cognitive structures and is sometimes even equated with MEC theory. Laddering refers to individual, face-to-face, semistructured interviews used to understand how consumers translate the attributes of products into meaningful associations with respect to self, following MEC theory (Reynolds \& Gutman, 1988). Based on a series of directed probes (typified by the question "Why is the product important to you?"), laddering is particularly suitable for tracing the perceptual hierarchy from salient attributes that the consumer uses to distinguish the product up to higher levels of abstraction corresponding to the consequences of product use and desired values. Accordingly, repetitive and interactive questions are used to elicit progressively more abstract elements, and thereby to obtain in-depth information about the range of concepts constituting the MEC content: product attributes (A), consequences (C), and values (V) attributable to the product. For our cross-cultural analysis of MEC linkages relative to wine consumers' 
purchases, we determined sets of key perceptual elements involved in the decision-making process of French and Korean consumers. Table 1 provides the constitutive elements of the cognitive structures, sequentially elicited from laddering interviews with 10 wine consumers in each country respectively.

Table 1. Constitutive elements of MEC for wine purchase decisions

\begin{tabular}{l|l|l}
\hline \multicolumn{1}{c|}{ Attributes } & \multicolumn{1}{c}{ Consequences } & \multicolumn{1}{c}{ Values } \\
\hline A1-Flavor & C1-Match personal taste & V1-Hedonism \\
\hline A2-Color & C2-Impress others & V2-Self-fulfilment \\
\hline A3-Brand & C3-Mood enhancement & V3-Sense of belonging \\
\hline A4-Grape variety & C4-Health benefits & V4-Excitement \\
\hline A5-Harvest year & C5-Avoid negatives & V5-Being well respected \\
\hline A6-Recommendation & C6-Good value for money & V6-Warm relationship with others \\
\hline A7-Region of origin & C7-Marriage of food and wine & V7-Security \\
\hline A8-Price & C8-Match others & V8-Self-respect \\
\hline A9-Reputation & C9-New experience & V9-Sense of accomplishment \\
\hline A10-Quality & C10-Pleasing to palate & V10-Benevolence \\
\hline Notes: Our in-depth one-on-one interviews & renthe
\end{tabular}

Notes: Our in-depth one-on-one interviews were administered respectively in France in French and in South Korea in Korean. The requirements for participation in Laddering were that participants be at least 19 years of age and consume and purchase wine at least once per month.

\section{Analytic and Holistic Processing of Cognition}

Markus and Kitayama (1991) argue that individuals in Eastern societies tend to think of themselves in terms of their connectedness with others in the context of the larger social world, whereas individuals in Western societies are more likely to think of themselves in terms of their unique personal traits and their separateness from others and social context. These cross-cultural differences in self-representation—interdependent or independent—are viewed as promoting different procedural modes of thinking. The interdependent self is associated with a tendency to perceive objects in terms of the whole or the context within which they are presented, while the independent self reflects a tendency to process the various components separately, as if they were unaffected by the given context and situation (Choi et al., 2003; Kühnen et al., 2001; Markus \& Kitayama, 1991). As such, cognitive psychologists have demonstrated the potential impact of self-view on cognitive processing style by describing the dichotomy between cultural perspectives - holistic (analytic) thinking encouraged in Eastern (Western) cultures. More specifically, holistic thinking is defined as involving an orientation to the context or field as a whole, including attention to relationships between a focal object and the field, and a preference for explaining and predicting events on the basis of such relationships (Nisbett et al., 2001). Contrarily, analytic thinking involves an emphasis on a salient object independent of its context, a tendency to focus on the attributes of the object to assign it to categories, and a preference for using rules about the categories to explain and predict the object's behavior (Nisbett et al., 2001).

These distinct differences between holistic and analytic thinking styles have implications for fundamental cultural differences in the pattern of making causal attributions to individuals' behavior. Westerners and Easterners use different cognitive approaches when trying to predict and explain the causes of behavior and events. Indeed, Easterners are more likely to attribute causes to the broader context and to implement holistic solutions by tracing behavior to person-context interactions, i.e., contextual or external attribution tendencies, whereas Easterners favor attributing causes to the presumed personal attributes by ignoring situational causes, i.e., dispositional or internal attribution tendencies (Morris \& Peng, 1994; Norenzayan, Choi, \& Nisbett, 2002). It is widely acknowledged that Easterners possess relatively more holistic ideas about the universe in general and more complex beliefs about causal reasoning in particular than do Westerners (Morris, Nisbett, \& Peng, 1995; Hong et al., 2000). Likewise, the more holistic reasoners tend to consider a more diverse set of information as potentially relevant to causal analysis and thereby assume the presence of complex causality (Choi et al., 2003).

In our research, we focus on the fact that Easterners have a stronger holistic view of causality, and thus take into consideration a greater amount of information (both focal and contextual information) to make a decision than do their Western counterparts. Consequently, it would seem to follow that such different cognitive activity affects the way in which consumers cognitively connect perceptual MEC elements to each other across the range of attributes, consequences, and values. That is, this research attempts to clarify whether cultural differences in styles of thinking cause cultural differences in the number of MEC linkages underlying wine consumers' decision processes. It is 
suggested that holistic consumers, compared to analytic consumers, will be likely to generate a greater number of relationships between MEC constitutive elements, and then to develop more complex cognitive structures when selecting wine.

\section{Priming: Cultural Frame Switching in Cognitive Performance}

The dynamic approach views cultural differences as flexible and dynamic, not fixed or static, showing that individuals can switch between various cultural frames of reference in response to corresponding social cues (e.g., Gardner, Gabriel, \& Lee, 1999; Hong et al., 2000, 2003; Kühnen \& Oyserman, 2002). Previous studies have shown that cultural knowledge depends on the relative cognitive accessibility of the cultural frames at a given time, more specifically that cultural priming manipulations can activate, in the perceiver's mind, particular pieces of cultural knowledge used to guide their cognition and judgment. The technique of cultural priming makes use of the fact that all individuals can possess multiple cultural knowledge structures for the same domain and that they can be induced experimentally to rely on given culture-specific knowledge in interpreting stimuli (Hong et al., 2000).

In particular, regardless of an individual's cultural background, the two styles of thinking can selectively be activated by salient contextual cues related to the cultural aspects. Kühnen, Hannover, and Schubert (2001), for example, observed shifts in individuals' self-view and corresponding styles of thinking using cultural primes: Semantically priming the independent (interdependent) self-increased the cognitive accessibility of autonomous (social) aspects of the self and momentarily induced context-independent (dependent) thinking. Thus, making a particular way of viewing the self-more available should lead an individual to adopt a thinking style congruent with the primed self (Kühnen \& Oyserman, 2002). Furthermore, Hong et al. (2000) provided compelling evidence that cultural priming affected the likelihood of making dispositional attributions or situational attributions concerning social behaviors: Individuals exposed to East Asian cultural icons interpreted behavior as caused more externally and contextually than did individuals primed with American cultural icons.

In line with these findings, it is believed that the assumption that Easterners are born to be holistic and Westerners are primarily analytic may be too simplistic, and that contextual cues (cultural primes) will determine the activated cultural self-view, thereby resulting in culture-specific cognitive processing styles. We suggest, therefore, that the relative salience of analytic versus holistic thinking can be manipulated experimentally by means of priming, in which the activation level of the specific mode of thinking is increased through the presentation of a stimulus semantically related to corresponding self-view.

In sum, a considerable body of research supports the greater ability of holistic thinkers to emphasize the interaction between objects and to take more information into consideration in causal understanding compared to analytic thinkers. Notably, it might therefore be expected that consumers from Eastern cultures, characterized as holistic reasoners, will mentally create a greater number of combinations between relevant MEC elements than consumers from Western cultures, characterized as analytic reasoners. In addition, in our research on the influence of crosscultural differences in cognition on the complexity of MEC linkages, we use the concept of temporary accessibility and the technique of cultural priming to manipulate the two conflicting styles of thinking. Specifically, this research was also designed to examine within-cultural group variation in the number of sequences of attributes, consequences, and values consumers consider in making a wine purchase decision. To do so, we experimentally primed French and Korean wine consumers to make available or activate either the analytic or the holistic styles of thinking in their minds, and then probed the consequences in terms of their cognitive complexity underlying the consumption choice for wine. If consumers' styles of thinking are indeed responsible for cultural differences in total quantity of hierarchical MEC relationships wine consumers consider, then priming holistic thinking should increase the number of Western consumers' cognitive linkages, whereas priming analytic thinking should reduce the number of Eastern consumers' cognitive linkages. To conclude, we propose that:

H1: Without priming, consumers from Eastern cultures will make a greater number of MEC linkages considered in wine purchase decision making than consumers from Western cultures.

H2: Priming holistic thinking among Western consumers will increase the number of MEC linkages considered in wine purchase decision making, whereas priming analytic thinking among Eastern consumers will reduce the number of MEC linkages considered. 


\section{RESEARCH METHODOLOGY}

\section{General Study Design}

To demonstrate the robustness of the effects of priming analytic and holistic thinking, we conducted our experiment in two cultural settings - in France and also in Korea. The hypotheses were tested through an experimental design employing a 2 (culture: French, Korean) x 3 (priming: no priming, analytic priming, holistic priming) betweensubjects factor analysis. Participants in both cultural groups were randomly assigned to one of the three experimental conditions. A non-priming control condition was included to compare the results of "chronic activation" of analytic or holistic thinking encouraged by each culture and "situational activation" by priming selected cognitive modes within a cultural group. Following the priming activity, participants were given the stimulus materials - measures of MEC linkages in a wine purchasing context. We explained both the priming task and measurement of the dependent variable beforehand to minimize the temporal interval between the two phases of our experimental procedure, which were presented as two independent studies.

\section{Participants}

The research participants were 157 French undergraduates $\left(66 \%\right.$ female, $M_{\text {age }}=20.95$ years, SD $=2.39$ years; home language $=100 \%$ French $)$ from a university in Paris and 171 Korean undergraduates $\left(59 \%\right.$ female, $M_{\text {age }}=22.07$ years, $\mathrm{SD}=3.21$ years; home language $=100 \%$ Korean) from a university in Seoul. All French (Korean) students who participated in the study identified themselves as being of French (Korean) descent, having lived in France (Korea) for their entire lives. All participants reported both consuming and purchasing wine at least once per month. Our experimental design was administered in exactly the same way at the two universities for both cultural groups.

\section{Priming manipulations}

Participants' analytic or holistic thinking styles were made temporarily more accessible via self-view priming manipulation adapted from Aaker and Williams (1998). Participants were exposed to a fictitious advertisement representing the independent self or interdependent self, or a neutral prime. The assignment of the participants to the two experimental conditions and the control condition was random. Participants in the analytic condition were shown an advertisement featuring an individual alone accompanied by the caption:

"I remember a day by myself at the beach. I hear the sound of the surf crashing on the beach. I feel joy and happiness in the bright light of the sun shining on me. I would like to extend these precious moments for myself without being disturbed by other people!" (See Appendix 1.)

Participants in the holistic condition received an advertisement featuring a group of friends or family accompanied by the caption:

"I remember a day with my family and friends at the beach. We hear the sound of the surf crashing on the beach. We feel joy and happiness in the bright light of the sun shining on us. We would like to extend these precious moments for ourselves without being disturbed by other people!" (See Appendix 2.)

Participants were then asked to form an impression of the given advertisement. Recent studies suggest that priming a self-view effectively activates a different cognitive style in one's mind, making information congruent with the primed self temporarily more accessible (Kühnen et al., 2001; Kühnen \& Oyserman, 2002; Ng \& Huston, 2006). We thus expect that increasing the accessibility of a particular aspect of the self can promote related networks of cultural thinking styles. In our research, priming the independent (interdependent) self was intended to increase the level of activation of the analytic (holistic) cognitive processing style.

\section{Measurement of MEC Linkages}

Immediately after the cultural priming procedure, participants were introduced to the quantitative measurement for assessing hierarchical MEC relationships and were shown the association pattern matrix (APM) technique designed 
by Hofstede et al. (1998). APM is a quantitatively oriented method for uncovering MEC linkages, suitable for largescale samples of consumers, particularly in international marketing research. In APM, the MEC is conceived as a string of connected matrices, an (attribute-consequence) A-C matrix and a (consequence-value) $\mathrm{C}-\mathrm{V}$ matrix, which are independent of each other and are measured separately. Applying the structured APM method requires exploratory research to identify the main concepts to be included in the two matrices (Hofstede et al., 1998). Accordingly, our predefined set of attributes, consequences, and values that constitute the content of wine consumer's MEC were transferred to the matrices and presented as a paper-and-pencil test in a questionnaire format. Figure 1 gives an example of a section of the $\mathrm{A}-\mathrm{C}$ and $\mathrm{C}-\mathrm{V}$ matrices used in our experimental study. In the $\mathrm{A}-\mathrm{C}$ $(\mathrm{C}-\mathrm{V})$ matrix, participants were presented with the attributes (consequences) and consequences (values), respectively listed in the columns and rows. Thus each matrix includes all possible association networks between the elements provided. Participants simply checked the corresponding cell in the given matrix to indicate MEC connections they value when selecting wine. To ensure that the priming and APM materials correctly conveyed the same meaning in both cultures, we performed the standard technique of back translation (Hui \& Triandis, 1989).

Figure 1. Example of the $\mathrm{A}-\mathrm{C}$ and $\mathrm{C}-\mathrm{V}$ matrices for wine purchase decisions

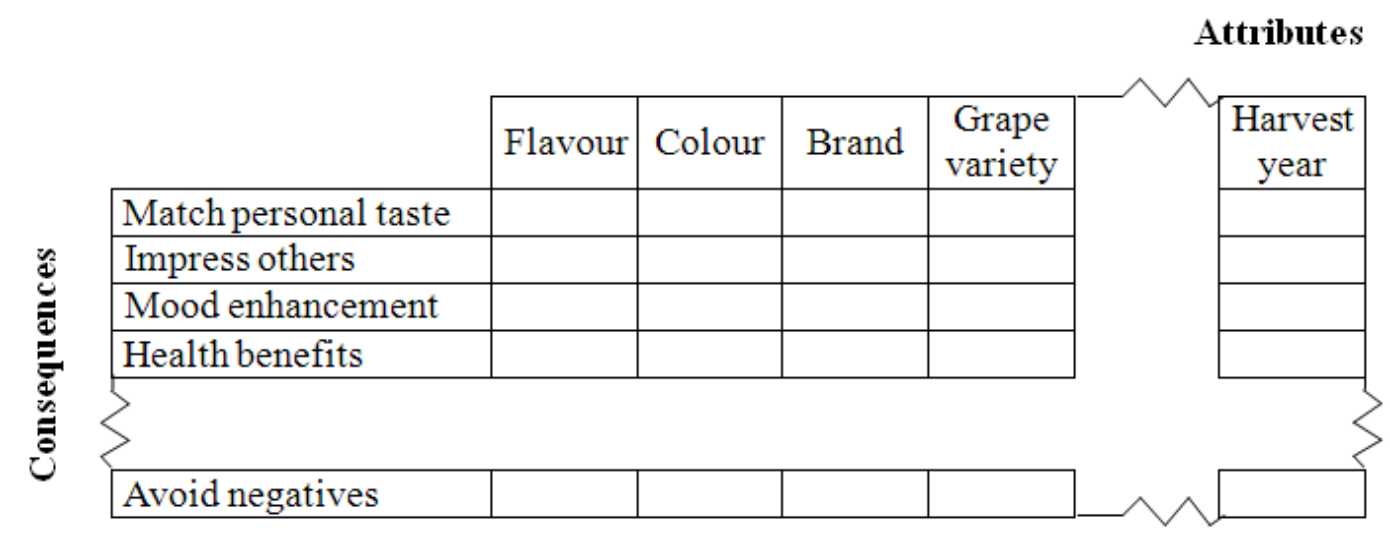

Consequences

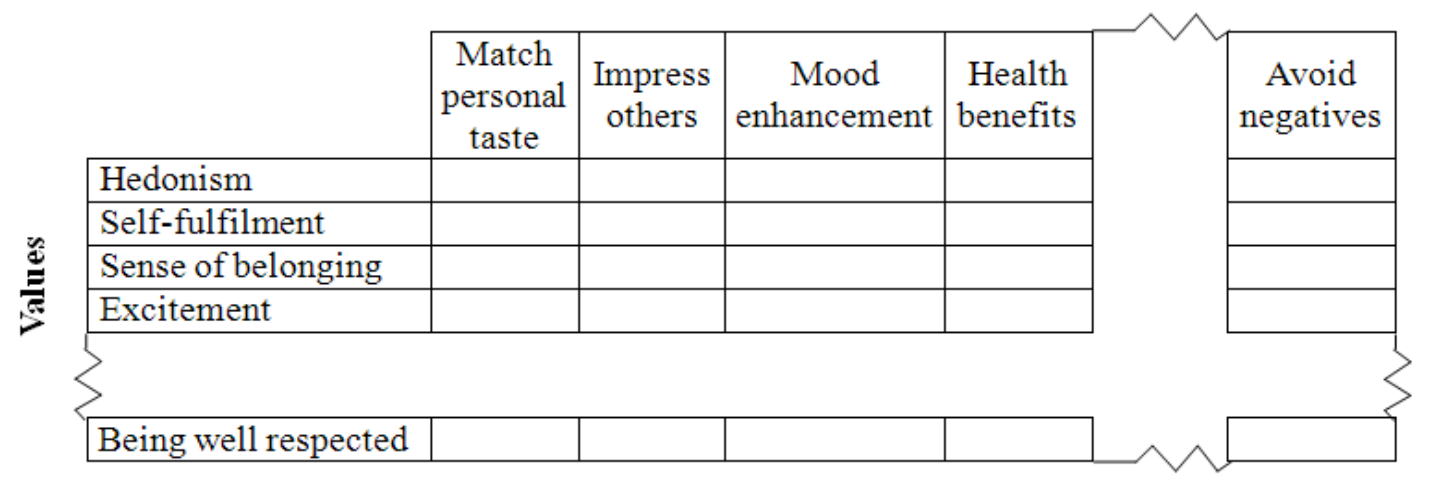

RESULTS

\section{Quantitative Variations in A-C and C-V Linkages}

We examined the relationship between cultural differences in wine consumers' thinking styles and cultural differences in the number of MEC linkages they consider. The aggregate numbers of A-C and C-V linkages for our control and experimental groups were calculated by averaging all the cognitive linkages each participant indicated in the corresponding matrices. The $\mathrm{A}-\mathrm{C}$ and $\mathrm{C}-\mathrm{V}$ linkages generated were subjected to a 2 (culture) $\mathrm{x} 3$ (prime) ANOVA with, culture and priming mechanism as a between-subjects factor. We first explored whether Korean participants considered a greater number of cognitive linkages when buying wine than French participants. Planned 
comparisons confirmed that there were significant differences between the two cultural groups (in the non-priming condition $)$ in the means of $\mathrm{A}-\mathrm{C}$ linkages $(F(1,322)=12.31 ; p=<.001)$ and $\mathrm{C}-\mathrm{V}$ linkages $(F(1,322)=7.92 ; p<$ .01 ; see Table 2 for means and standard deviations). Consistent with H1, we found that a greater number of MEC linkages emerged in Korean consumers' cognitive structures compared to their French counterparts.

Table 2. Mean numbers of $\mathrm{A}-\mathrm{C}$ and $\mathrm{C}-\mathrm{V}$ linkages

\begin{tabular}{c|c|c|c|c|c|c}
\hline & \multicolumn{3}{|c|}{ French consumers } & \multicolumn{3}{c}{ Korean consumers } \\
\hline $\begin{array}{c}\text { MEC } \\
\text { linkages }\end{array}$ & $\begin{array}{c}\text { No priming } \\
(\boldsymbol{n}=\mathbf{5 2})\end{array}$ & $\begin{array}{c}\text { Analytic priming } \\
(\boldsymbol{n}=\mathbf{5 0})\end{array}$ & $\begin{array}{c}\text { Holistic priming } \\
(\boldsymbol{n}=\mathbf{5 5})\end{array}$ & $\begin{array}{c}\text { No priming } \\
(\boldsymbol{n}=\mathbf{5 3})\end{array}$ & $\begin{array}{c}\text { Analytic priming } \\
(\boldsymbol{n}=\mathbf{5 8})\end{array}$ & $\begin{array}{c}\text { Holistic priming } \\
(\boldsymbol{n}=\mathbf{6 0})\end{array}$ \\
\hline \multirow{2}{*}{$\mathrm{A}-\mathrm{C}$} & 12.53 & 12.27 & 14.86 & 16.15 & 13.62 & 16.93 \\
& $(1.94)$ & $(2.31)$ & $(2.01)$ & $(2.56)$ & $(1.54)$ & $(2.09)$ \\
\hline \multirow{2}{*}{$\mathrm{C}-\mathrm{V}$} & 10.77 & 11.03 & 13.12 & 13.58 & 10.19 & 14.07 \\
& $(2.23)$ & $(1.85)$ & $(1.74)$ & $(2.18)$ & $(1.89)$ & $(1.61)$ \\
\hline
\end{tabular}

Notes: Standard deviations shown in parentheses; $\mathrm{A}-\mathrm{C}=$ attributes-consequences linkages; $\mathrm{C}-\mathrm{V}=$ consequences-values linkages.

In addition, we examined whether the number of linkages considered by wine consumers varied at an individual level after being primed for analytic versus holistic thinking within each culture. As predicted, the interaction effects were found to be significant between culture and priming for A-C linkages $(F(2,322)=3.97 ; p<.05)$ and $\mathrm{C}-\mathrm{V}$ linkages $(F(2,322)=6.12 ; p<.01)$, as shown in Table 2 (means and standard deviations). More specifically, while the holistic priming induced more cognitive linkages among French participants, the analytic priming induced fewer cognitive linkages among Korean participants. The results of our planned comparisons indicated that the French A$\mathrm{C}$ linkages were significantly more numerous in the holistic prime than in the non-priming condition $(F(1,214)=$ $6.93, p<.01)$; the Korean A-C linkages were significantly fewer in the analytic priming condition than in the nonpriming condition $(F(1,214)=8.75, p<.01)$. We further verified that French consumers primed with holistic thinking tended to consider a greater number of $\mathrm{C}-\mathrm{V}$ linkages than when in the neutral priming condition $(F(1,214)$ $=5.18, p<.01)$; Korean consumers accessed fewer $\mathrm{C}-\mathrm{V}$ linkages when analytic thinking was primed in contrast to the neutral priming condition $(F(1,214)=14.23, p<.001)$. In short, a visual summary of the means of MEC linkages (see Figures 2 and 3 ) highlights that quantitative variation in the number of cognitive linkages appeared in accordance with culturally relevant priming frames, broadly consistent with $\mathrm{H} 2$. These priming results thus provide evidence that a shift in thinking styles among French and Korean consumers plays a crucial role in the modulation of the cognitive approach guiding the $\mathrm{A}-\mathrm{C}-\mathrm{V}$ hierarchy structures involved in their wine choices.

Figure 2. Effect of cultural primes on the number of A-C linkages considered by wine consumers
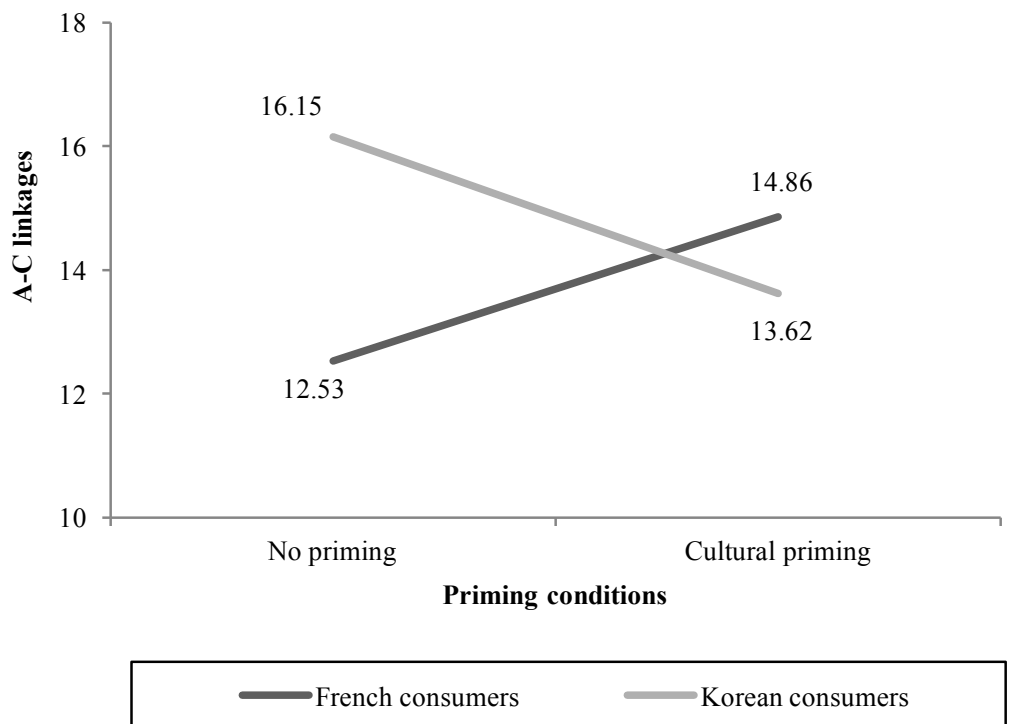

Notes: A-C $=$ attributes-consequences linkages; cultural priming $=$ holistic priming for French wine consumers and analytic priming for Korean wine consumers 
Figure 3. Effect of cultural primes on the number of $\mathrm{C}-\mathrm{V}$ linkages considered by wine consumers

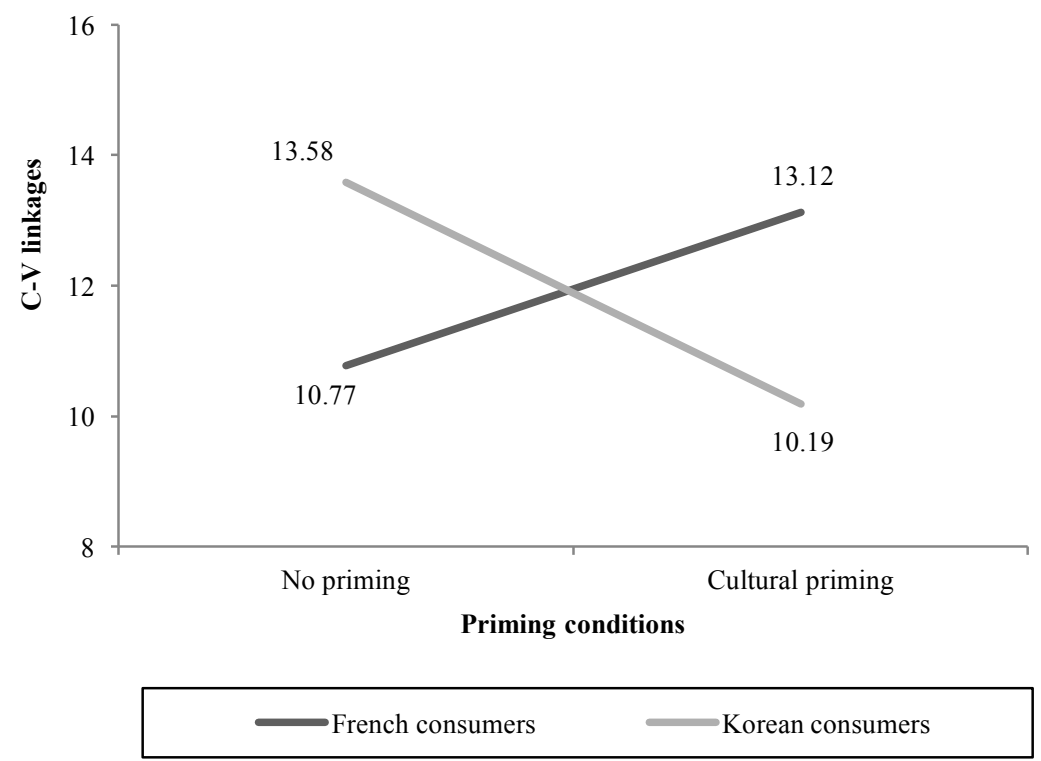

Notes: $\mathrm{C}-\mathrm{V}=$ consequences-values linkages; cultural priming = holistic priming for French wine consumers and analytic priming for Korean wine consumers

\section{MEC Linkage Complexity}

To reveal the cognitive structures in participants' minds, we aggregated all the linkages evoked in the form of a graphical representation, that is to say, we visualized the set formed by various relationships between all the attributes, consequences, and values related to wine purchases. The forms of $\mathrm{A}-\mathrm{C}-\mathrm{V}$ sequences are represented in hierarchical value maps (HVMs; Reynolds \& Gutman, 1988) of the consumer decision-making process based on the frequencies of linkages. Specifically, the construction of the HVMs enabled us to compare all possible combinations for the hierarchical relations made by two separate groups of wine consumers; all participants primed with analytic (holistic) thinking were taken as analytic (holistic) consumers, irrespective of their own cultural background. The entire contents of the MEC were presented in order of their assigned numbers across the range of three different levels of abstraction. A visual comparison of two HVMs (see Figures 4 and 5) demonstrates that the linkages between each element of content are considerably more numerous in the holistic consumers' MEC network than in the analytic consumers' one. We find that holistic consumers consider a large pool of hierarchical MEC relationships, such that they form more complex, even confusing, cognitive structures. Indeed, a given attribute (consequence) is associated with a greater number of consequences (values) in the holistic priming condition than in the analytic priming condition. Overall, in line with the results of the statistical analysis, the global observation of the HVMs reinforces the argument that the salience of analytic versus holistic thinking creates different complexity in the MEC with regard to consumers' decision-making processes concerning the purchase of wine. 
Figure 4. MEC network of wine consumers primed with holistic thinking

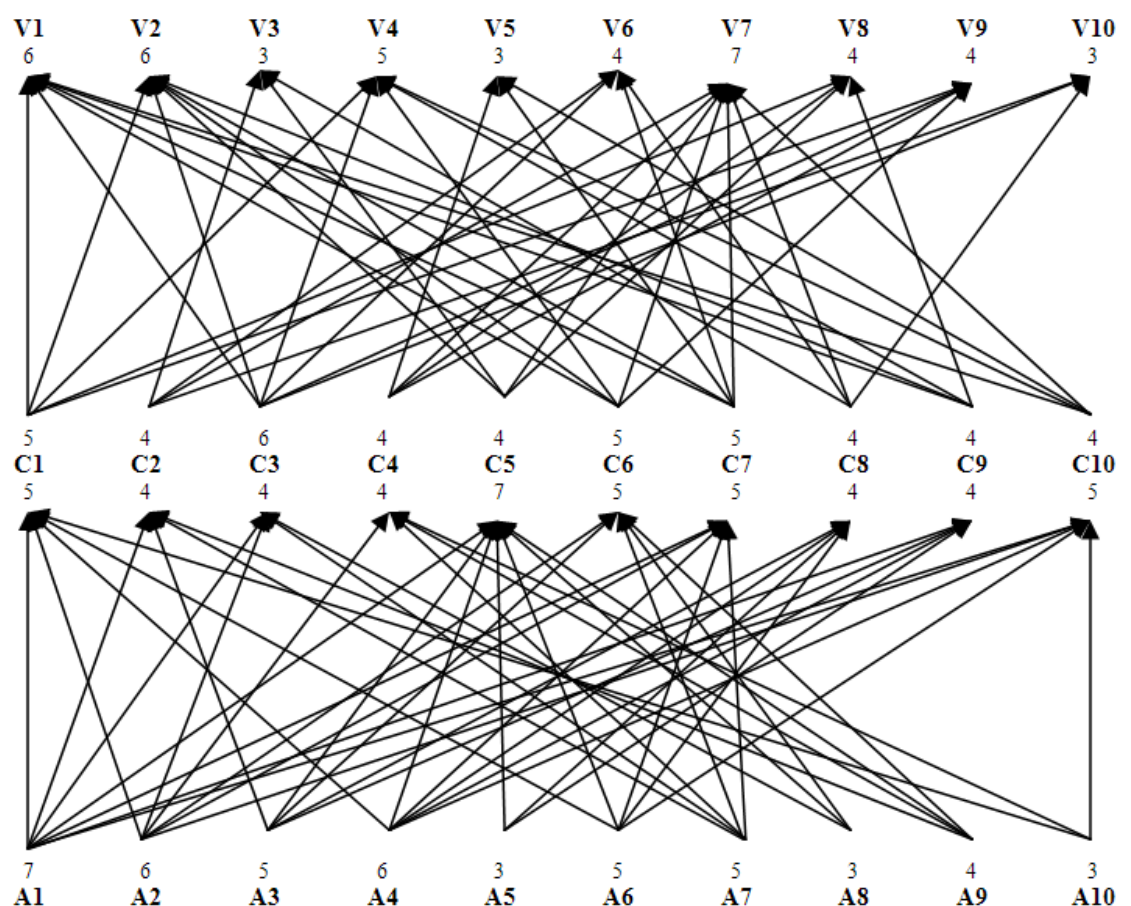

Notes: The number shown above (below) each MEC content indicates the number of elements connected upstream (downstream) of MEC network. The corresponding numbers of the attributes (A), consequences (C), and values $(\mathrm{V})$ are presented in Table 1.

Figure 5. MEC network of wine consumers primed with analytic thinking

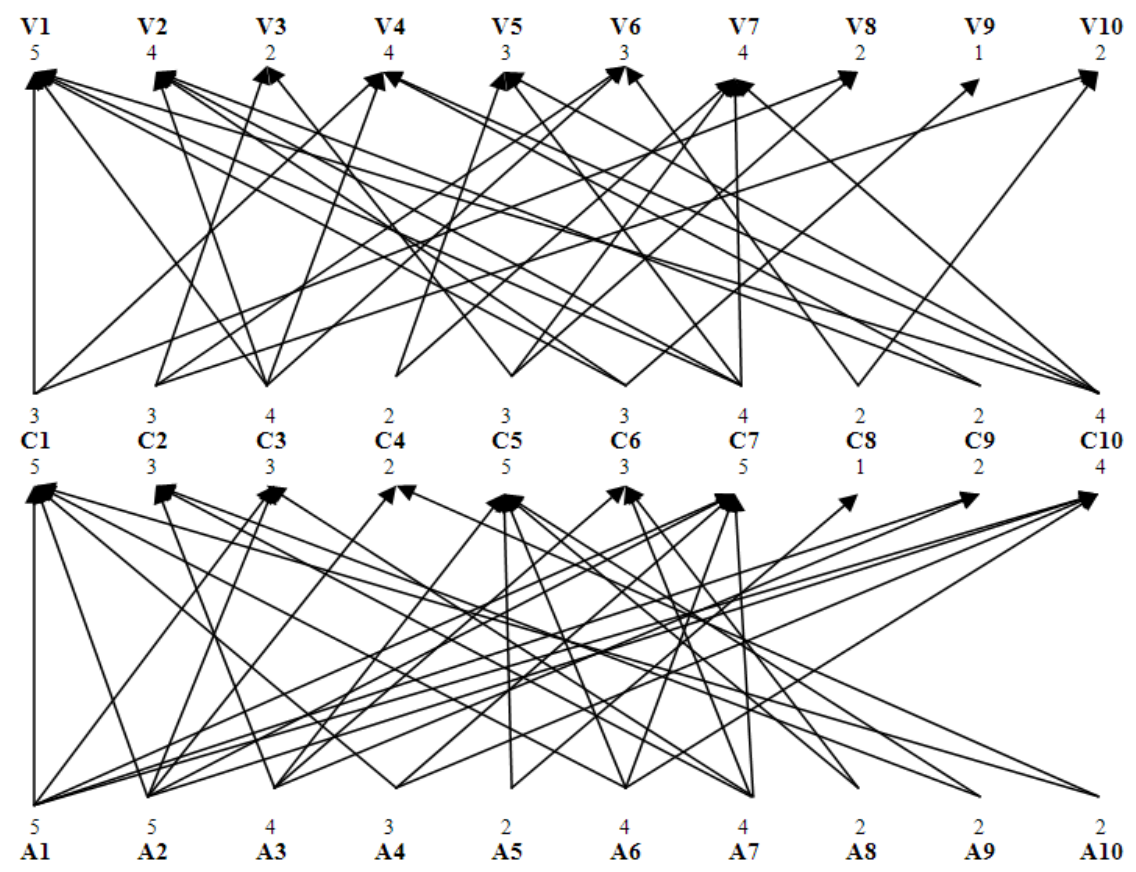

Notes: The number shown above (below) each MEC content indicates the number of elements connected upstream (downstream) of MEC network. The corresponding numbers of the attributes (A), consequences (C), and values (V) are presented in Table 1. 


\section{DISCUSSION}

The MEC approach has been particularly successful in exploring cross-cultural consumer mindsets and behavior in the food domain (e.g., Hofstede et al., 1999; Nielsen, Bech-Larsen, \& Grunert, 1998; Overby et al., 2004; Russel et al., 2004; Valette-Florence et al., 2000). Until now, MEC-related research has not explicitly considered the influence of consumers' cognitive processing styles on their hierarchical cognitive structures, although recent research from cross-cultural psychology has revealed that modes of thinking are different between Westerners with a dependent self-view and Easterners with an interdependent self-view. The primary purpose of this study was to examine whether consumers exhibited different cognitive complexity in consumption decisions, depending on which thinking style was salient. This idea was investigated in the context of wine consumers' purchases with two different cultural groups, French and Korean, believed to be analytic and holistic respectively within their own cultures. This study, using a priming paradigm in a cultural analysis of wine consumers' MEC linkages, has provided some clarification on the role of analytic versus holistic thinking in the consumer decision-making process. Thus, it contributes to recent research in food marketing by clarifying the different styles of thinking as a driving force for the potential cultural variation in the number of hierarchical relationships linking attributes, consequences, and values consumers consider in making a decision.

As holistic thinkers have a tendency to focus on relationships among objects and events, while analytic thinkers are inclined to focus on the attributes of a focal object divorced from its context (Choi et al., 2003; Nisbett et al. 2001), we hypothesized and confirmed that Korean wine consumers, compared to French wine consumers, would consider broader connections between the key perceptual elements of the MEC, resulting in more complex structures of interconnected motives. Specifically, drawing upon previous research validating that the two ways of viewing the self affect human cognition (Gardner et al., 1999; Kühnen et al., 2001; Markus \& Kitayama, 1991), we have demonstrated the effects of thinking style on MEC linkages after priming consumers with independent versus interdependent self-view prompts. In an experimental setting, we found that self-view priming differentially influences the number of $\mathrm{A}-\mathrm{C}$ and $\mathrm{C}-\mathrm{V}$ linkages engendered by two cultural groups, such that French (Korean) consumers exposed to contexts fostering an interdependent (independent) orientation, when compared to those in the non-priming condition, considered more (fewer) hierarchical MEC relationships. Thus, these findings suggest that different cognitive processing styles among French and Korean wine consumers can be induced through priming an independent or interdependent self-view, and that the thinking style consistent with situationally activated self-view can in turn affect the process by which they form sets of cognitive linkages between the product's attributes and their motivations to consume.

Furthermore, wine consumers' hierarchical cognitive structures are graphically represented in HVMs constructed based on individual $\mathrm{A}-\mathrm{C}$ and $\mathrm{C}-\mathrm{V}$ matrices to observe their mental images and networks related to wine purchase decisions. Splitting the total sample into analytic versus holistic consumers, regardless of culture, results in parallel patterns of cognitive complexity for French versus Korean consumers. The holistic thinking-primed consumers draw a highly complex MEC network containing a larger number of perceived connections across the range of attributes, consequences, and values than the analytic thinking-primed consumers. These consistent prime effects show that the thinking style associated with a particular self-view, even when temporarily activated, plays an important role in determining the structure of the $\mathrm{A}-\mathrm{C}-\mathrm{V}$ hierarchy underlying the consumer decision process. As a whole, the results provide support for our basic premise that cultural differences in the relative complexity of MEC linkages underlying consumers' wine-buying decision making are due to cultural differences in holistic tendency: Easterners take more complex relationships into consideration in the causal reasoning of the world than Westerners.

Consistent with the idea of analytic versus holistic thinking (Choi et al., 2003), and the perspective of culture as a dynamic construct (Hong et al., 2000), our overall findings may shed light on the variation in cognitive processing styles as a function of the shift in self-concept styles induced by self-view priming manipulation. What is particularly notable is the fact that our research presents a pattern of results consistent with those of Kühnen and Oyserman (2002), who demonstrated that the independent (interdependent) self is stored in a semantic networkautonomous (social) semantic knowledge of the self-which is connected to cognitive procedures of analytic (holistic) thinking, and that priming these different views of the self brings about an associated thinking mode influencing judgment and decision making. Therefore, our results also contribute to the dynamic understanding of culture-specific thinking styles by supporting the argument that the activation of a particular cognitive process 
depends on culture-priming cues encountered in a given situation (Hong et al., 2003; Morris \& Peng, 1994; Ng \& Huston, 2006). Interestingly, in comparison to prior research with Western participants, we believe that this is one of the first cross-cultural studies of consumer behavior to include both Western and Eastern participants who are thought to be dominated respectively by independent and interdependent self-views, as analytic and holistic thinkers. More importantly, what is unique about this study is the identification of consumers' cognitive styles as a determinant of cultural differences in the number of cognitive linkages between the attributes, consequences, and values that serve as a basis for decision making. Considering culturally encouraged versus situationally primed selfview, this cross-cultural investigation of MECs contributes to a better understanding of the flexibility of thinking styles in consumers, thereby emphasizing the importance of the accessibility of cultural mindsets in making product choice decisions. As such, these findings suggest the possibility of applying a dynamic perspective to culture and cognition in research on cross-cultural consumer behavior toward food. We hope that our experimental study of wine consumers' hierarchical cognitive structures will stimulate international food marketing researchers to explore the fundamental mechanisms that underlie cultural differences in consumer cognition and decision making in the food consumption context.

\section{MANAGERIAL IMPLICATIONS}

Our results indicate the tendency of Eastern consumers (holistic thinkers), compared to Western consumers (analytic thinkers), to pay more attention to the interaction between elements and then to consider more attributeconsequence-value sequences as relevant in evaluating products. Given the cognitive differences among consumers, different degrees of interconnected motivations driving their buying behavior appear to be required for purchase decisions. It is therefore conceivable that analytic and holistic consumers' attention to different amounts of information can give rise to different attitudes toward the advertisements they are exposed to. In this regard, this study provides practical suggestions to wine marketing managers worldwide, aiding in understanding consumers' cognitive complexity in wine consumption decisions and improving the persuasiveness of advertisements in international and cross-cultural contexts. To the extent that consumers in Eastern cultures attend to a wider scope of information, it might be helpful to design, especially in such cultures, advertisements which contain rich information concerning different attributes, consequences, and values as related to each other. Conversely, it would seem more appropriate that advertisers in Western cultures provide core information with unique and salient linkage to consumers' cognitive schema as consumers in such cultures are more likely to rely on internal attributes and specific details. An interesting managerial implication is thus that advertising appeals should be congruent with cultural thinking styles to be more persuasive, including multiple features and benefits (only a key selling point) of a product that holistic (analytic) consumers have a greater tendency to use to make purchase decisions.

This study has another important implication for international food business operators with regard to the priming of culturally relevant cues that facilitate the cognitive accessibility of specific cultural orientations. Our priming manipulations in France and Korea show that thinking of oneself as independent or interdependent can activate a culture-specific cognition, thus leading to quantitatively different consequences for MEC linkages. Hence, the current findings on priming may provide a powerful tool for understanding how an independent versus interdependent mindset generates the consideration of different amounts of information in consumer decisions regarding food choice. In this sense, it seems especially important for advertisers to consider the practical significance - a temporary switch in consumer's cognitive style in response to subtle contextual factors-when determining the amount of commercial information communicated in an advertisement. For instance, if a food product advertisement appears in the context of togetherness (the main character with friends or family), then this particular environmental cue is expected to prime consumers to think holistically, and consequently they will prefer holistic advertising with several different types of information concerning the product. However, when food product advertising appears in the context of uniqueness (the main character alone), it should be possible temporarily to increase a tendency to think analytically and thus evoke a more favorable response to advertising that focuses on indepth information about the superior attributes of the product. In sum, marketers need to bear in mind that consumer mindsets shaped by cultures can be malleable, based on incidental exposure to congruent cultural cues and contexts in advertising, and ultimately, that activating a holistic or analytic thinking style results in more or less complex cognitive processes underlying consumers' product judgments. Such in-depth consideration of the dynamic influences of culture on cognition and buying behavior may open up new ways of understanding culture-specific visual stimulation, such as an interdependent (independent) self-concept setting in international food marketing 
communications, which is considered to trigger greater consumer preference for holistic (focal) information needed in the purchase decision process.

\section{LIMITATIONS AND FUTURE RESEARCH}

The limitations of this study afford opportunities for further examination of consumers' MEC linkages related to cognitive differences across cultures. One limitation involves the use of only one product (i.e., wine). Furthermore, although our cross-cultural comparisons did employ matched sampling to eliminate plausible alternative explanations for cultural differences, the choice of convenience samples drawn from French and Korean undergraduate students may limit the generalizability of the results to a more representative and wider population. Hence, care should be taken in generalizing our findings to other product categories and whole populations of other consumers. Future studies need to be undertaken to investigate whether the culturally specific patterns of MEC linkages still occur in other food and wine contexts for more a diverse range of consumers in different cultures representing an independent (analytic) orientation or interdependent (holistic) orientation.

Another possible limitation of this research is that the divergent thinking styles were not actually measured. We inferred consumers' analytic or holistic tendency from experimental manipulations of the independent and interdependent self, based on previous priming studies on culture and cognition. Recently, Choi et al. (2007) constructed the analysis-holism scale for cross-cultural research to measure analytic versus holistic reasoning, such as locus of attention (parts versus whole) and causal theory (dispositional versus contextual). Administering this convenient measure of thinking style after priming may open up new possibilities for the direct examination of the various antecedents and consequences of consumers' cognitive differences. Potentially, future experiments can thus find which aspect of the analytic-holistic thinking dimension comes to be particularly salient due to priming independence or interdependence. Further research would help broaden our knowledge of the causal role of the consumer's self-view in determining cultural cognitive styles by using the analysis-holism scale as complementary tool for manipulation checking.

In summary, our findings may fruitfully be extended to naturalistic environments, such as retail food stores and restaurants. It would be worth trying to explore whether drawing on congruent contextual cues in real-world purchase situations also facilitates relevant cognitive processing styles, thereby giving rise to the cross-cultural variations in decision makers' hierarchical cognitive structures. We hope that this study linking chronic or activated thinking styles to the MEC framework will provide fresh avenues for much more international research on the relationships between analytic-holistic cognition and consumer decision making regarding food products.

\section{AUTHOR BIOGRAPHY}

Byung-Joon Choi holds a Ph.D. degree in Marketing from the Pantheon-Assas Paris II University in France. Currently he is a Lecturer of the School of Management Sciences at Pantheon-Assas Paris II University. His main research interests focus on topics related to cross-cultural consumer behavior, consumers' information processing styles and decision-making, and consumer psychology.

\section{REFERENCES}

Aaker, J., \& Williams, P. (1998). Empathy versus Pride: The influence of emotional appeals across cultures. Journal of Consumer Research, 25, 241-261.

Choi, I., Koo, M., \& Choi, J. A. (2007). Individual differences in analytic versus holistic thinking. Personality and Social Psychology Bulletin, 33, 691-705.

Choi, I., Park, H., Dalal, R., \& Kim-Prieto, C. (2003). Culture and judgment of causal relevance. Journal of Personality and Social Psychology, 84, 46-59.

Gardner, W. L., Gabriel, S., \& Lee, A. Y. (1999). I value freedom, but We value relationships: self-construal priming mirrors cultural differences in judgment. Psychological Science, 10, 321-326.

Grunert, K., Lähteenmäki, L., Nielsen, N., Poulsen, J., Ueland, O., \& Åström, A. (2001). Consumer perceptions of food products involving genetic modification-results from a qualitative study in four Nordic countries. Food Quality and Preference, $12,527-542$.

Gutman, J. (1982). A means-end chain model based on consumer categorization processes. Journal of Marketing, 46, 60-72. 
Hofstede, F., Aubenaert, J. B., Steenkamp, E. M., \& Wedel, M. (1998). An investigation into the association pattern technique as a quantitative approach to measuring means-end chains. International Journal of Research in Marketing, 15, 37-50.

Hofstede, F., Steenkamp, E. M., \& Wedel, M. (1999). International market segmentation based on consumer-product relations. Journal of Marketing Research, 36, 1-17.

Hong, Y., Benet-Martinez, V., Chiu, C. Y., \& Morris, M. W. (2003). Boundaries of cultural influence: Construct activation as a mechanism for cultural differences in social perception. Journal of Cross-Cultural Psychology, 34, 453-464.

Hong, Y., Morris, M., Chiu, C.Y., \& Benet-Martínez, V. (2000). Multicultural minds: A dynamic constructivist approach to culture and cognition. American Psychologist, 55, 709-720.

Hui, C. H., \& Triandis, H. C. (1989). Effects of culture and response format on extreme response style. Journal of Cross-Cultural Psychology, 20, 296-309.

IWRS (2015). The IWRS (International Wine and Spirit Record) Drinks Record, June 05, 1.

Kühnen, U., Hannover, B., \& Schubert, B. (2001). The semantic-procedural interface model of the self: The role of selfknowledge for context-dependent versus context-independent modes of thinking. Journal of Personality and Social Psychology, 80, 397-409.

Kühnen, U., \& Oyserman, D. (2002). Thinking about the self influences thinking in general: cognitive consequences of salient self-concept. Journal of Experimental Social Psychology, 38, 492-499.

Markus, H. R., \& Kitayama, S. (1991). Culture and self: implications for cognition, emotion and motivation. Psychological Review, 98, 224-253.

Morris, M., Nisbett, R. E., \& Peng, K. (1995). Causal understanding across domains and cultures. In D. Sperber, D. Premack, \& A. J. Premack (Eds.), Causal cognition: A multidisciplinary debate (pp. 577-612). Oxford, England: Oxford University Press.

Morris, M., \& Peng, K. (1994). Culture and cause: American and Chinese attributions for social and physical events. Journal of Personality and Social Psychology, 67, 949-971.

Mort, G., \& Rose, T. (2004). The effect of product type on value linkages in the means-end chain: implications for theory and method. Journal of Consumer Behavior, 3, 221-234.

Ng, S., \& Houston, M. J. (2006). Exemplars or beliefs? The impact of self-view on the nature and relative influence of brand associations. Journal of Consumer Research, 32, 519-529.

Nielsen, N.A., Bech-Larsen, T., \& Grunert, K.G. (1998). Consumer purchase motives and product perceptions: a laddering study on vegetable oil in three countries. Food Quality and Preference, 9, 455-466.

Nisbett, R. E., Peng, K., Choi, I., \& Norenzayan, A. (2001). Culture and systems of thought: Holistic vs. analytic cognition. Psychological Review, 108, 291-310.

Norenzayan, A., Choi, I., \& Nisbett, R. E. (2002). Cultural similarities and differences in social inference: Evidence from behavioral predictions and lay theories of behavior. Personality and Social Psychology Bulletin, 28, 109-120.

Olson, J. C., \& Reynolds, T. J. (1983). Understanding consumer's cognitive structures: implications for advertising strategy. Advertising and Consumer Psychology, 1, 77-90.

Overby, J. W., Gardial, S. F., \& Woodruff, R. B. (2004). French versus American consumers' attachment of value to a product in a common consumption context: a cross-national comparison. Journal of the Academy of Marketing Science, 32, 437460 .

Peter, P. J., \& Olson, J. C. (2005). Consumer Behaviour and Marketing Strategy. New York, NY: McGraw Hill.

Reynolds, T.J. (1985). Implications for value research: A micro versus macro perspective. Psychology and Marketing, $2,297-$ 305 .

Reynolds, T. J., \& Gutman, J. (1988). Laddering theory, method, analysis and interpretation. Journal of Advertising Research, $28,11-31$

Russell, C., Busson, A., Flight, I., Bryan, J., van Lawick van Pabst, J., \& Cox, D. (2004). Comparison of three laddering techniques applied to an example of a complex food choice. Food Quality and Preference, 15, 569-583.

Valette-Florence, P., Sirieix, L., Grunert, K., \& Nielsen N. (2000). Means-end chain analyses of fish consumption in Denmark and France: A multidimensional perspective. Journal of Euromarketing, 8, $15-27$. 
APPENDIX A. Analytic priming condition for French and Korean wine consumers

Je me balade le long de la plage en passant mon temps à relaxer et à jouir du beau temps.

Je sens avec délice les rayons du soleil qui me caressent les joues, et j'entends le bruit que font les vagues qui déferlent sur la plage.

J'aimerais prolonger ces moments précieux pour moi sans être gênés par personne.

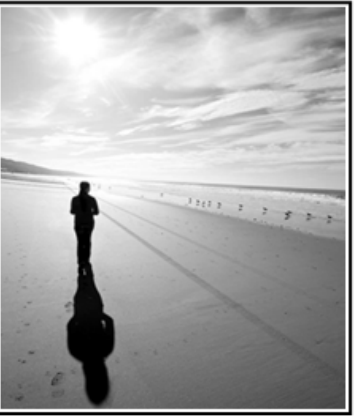

해변에서 나만의 즐겁고 여유로운 시간을 보내며 산책을

즐깁니다.

나에게 쏟아지는 따뜻한 햇살을 받으며, 해변으로 밀려드

는 부서지는 파도소리와 함께

그 무엇도 나만의 소중한 시간을 깨뜨릴 수 없습니다.

그 누구에게도 방해 받지 않는 나만의 휴식을 보내고 싶 습니다.

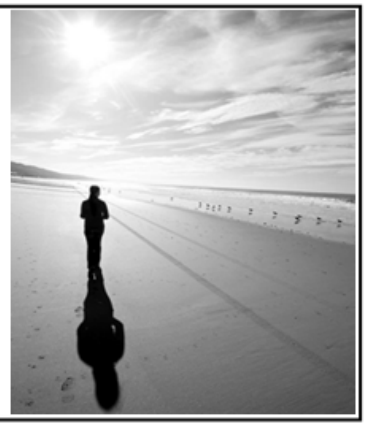


APPENDIX B. Holistic priming condition for French and Korean wine consumers

Nous nous baladons le long de la plage en passant notre temps à relaxer et à jouir du beau temps.

Nous sentons avec délice les rayons du soleil qui nous caressent les joues, et nous entendons le bruit que font les vagues qui déferlent sur la plage.

Nous aimerions prolonger ces moments précieux pour nous sans être gênés par personne.

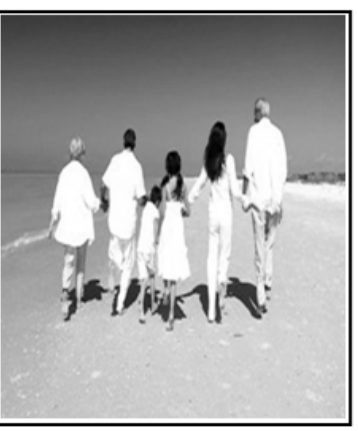

해변에서 우리만의 즐겁고 여유로운 시간을 보내며 산책 을 즐깁니다.

우리에게 쏟아지는 따뜻한 햇살을 받으며, 해변으로 밀려 드는 부서지는 파도소리와 함께

그 무엇도 우리들의 소중한 시간을 깨뜨릴 수 없습니다.

그 누구에게도 방해 받지 않는 우리만의 휴식을 보내고 싶습니다.

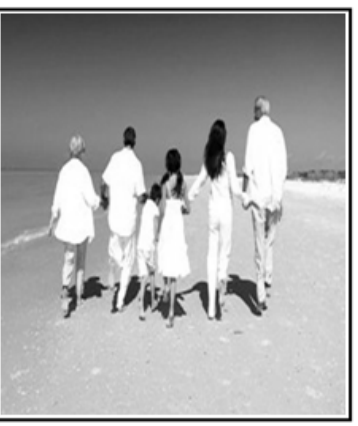


NOTES 